\title{
Spectrophotometric and Multivariate Calibration Techniques for Simultaneous Determination of Different Drugs in Pharmaceutical Formulations and Human Urine: Evaluation of Greenness Profile
}

\author{
Ahmed Mostafa (1D \\ Department of Pharmaceutical Chemistry, College of Clinical Pharmacy, Imam Abdulrahman Bin Faisal University, \\ King Faisal Road, P.O. Box 1982, Dammam 31441, Saudi Arabia \\ Correspondence should be addressed to Ahmed Mostafa; ammostaf@uwaterloo.ca
}

Received 9 April 2020; Accepted 1 May 2020; Published 29 May 2020

Academic Editor: Antonio V. Herrera-Herrera

Copyright (c) 2020 Ahmed Mostafa. This is an open access article distributed under the Creative Commons Attribution License, which permits unrestricted use, distribution, and reproduction in any medium, provided the original work is properly cited.

\begin{abstract}
Eco-friendly, rapid, and cost-effective two spectrophotometric methods were developed and validated for the determination of atenolol, paracetamol, hydrochlorothiazide, and levofloxacin. The first method is the newly developed extended derivative ratio (EDR) and the second method is multivariate curve resolution-alternating least squares (MCR-ALS). In the EDR method, the extended derivative ratio amplitudes at 281.6, 237.6, 279.2, and $282.8 \mathrm{~nm}$ were used for quantification of atenolol, paracetamol, hydrochlorothiazide, and levofloxacin, respectively. In the MCR-ALS method, calibration model was developed and correlation constraint was employed. External validation data set composed of seven mixtures was used, and different figures of merits such as root mean square error of prediction, standard error of prediction, bias, and relative error of prediction were calculated, and satisfactory results were obtained. Both methods provided comparable results. The methods were validated and applied for the determination of the target analytes in dosage forms, spiked and real human urine. Thereafter, the obtained results were statistically compared to the published methods and revealed no significant difference regarding accuracy and precision. Furthermore, the greenness profile of the methods was evaluated using the National Environmental Methods Index "NEMI" and Analytical Eco-Scale. The developed methods can be used as a valid eco-friendly and simple cost-effective alternative to the commonly used chromatographic methods for the routine analysis of the studied drugs in dosage forms and human urine.
\end{abstract}

\section{Introduction}

Atenolol (AT) (Figure 1(a)) is a selective $ß 1$ receptor blocker and is used for the treatment of hypertension and coronary heart disease. AT undergoes little or no metabolism in the liver and is mainly excreted in urine (over $85 \%$ of the absorbed drug is excreted in urine as unchanged drug) [1]. Different analytical techniques have been reported for the analysis of AT such as high performance liquid chromatography (HPLC) [2-4], spectrophotometric $[2,5,6]$, capillary electrophoresis $[7,8]$, gas chromatography (GC) [9], and spectrofluorimetric [10] methods.

Paracetamol (PR) or acetaminophen (Figure 1(b)) is an over-the-counter (OTC) analgesic and antipyretic drug. PR is metabolized in liver and mainly excreted in urine. Around $1-4 \%$ of the administered dose is excreted unchanged [11]. However, $47-62 \%$ of the dose is excreted as paracetamol conjugated to glucuronide and $25-36 \%$ as sulphate conjugates $([12,13]$. A small amount $(8-10 \%)$ is metabolized through oxidation to form cysteine and mercapturic acid conjugates [13].

Various studies can be found in the literature for the analysis of PR including HPLC [14-17], GC [18], spectrophotometry $[19,20]$, voltammetry $[21]$, and electrophoresis [22].

Hydrochlorothiazide (HZ) (Figure 1(c)) is a thiazide diuretic that is used to treat hypertension and edema associated with certain disease conditions such as congestive 
<smiles>CC(C)NCC(O)COc1ccc(CC(N)=O)cc1</smiles>

(a)<smiles>CC(=O)Nc1ccc(O)cc1</smiles><smiles>NS(=O)(=O)c1cc2c(cc1Cl)NCNS2(=O)=O</smiles><smiles>C[C@H]1COc2c(N3CCN(C)CC3)c(F)cc3c(=O)c(C(=O)O)cn1c23</smiles>

(c)

(d)

Figure 1: Chemical structures of atenolol (a), paracetamol (b), hydrochlorothiazide (c), and levofloxacin (d).

heart failure. $\mathrm{HZ}$ is excreted (>95\%) as unchanged drug in urine $[23,24]$. Different techniques have been reported for HZ quantitation such as HPLC [25-28], GC [29], spectrophotometry [30, 31], and voltammetry [32].

Levofloxacin (LV) (Figure 1(d)) is a fluoroquinolone antibiotic that inhibits DND topoisomerase IV and gyrase in Gram-positive and Gram-negative bacteria, respectively. It is used for urinary, respiratory, skin, and soft tissue infections [33]. Several reports are found in the literature for the determination of LV including different techniques such as HPLC [34, 35], spectrophotometry [34, 36], voltammetry [37], and capillary electrophoresis [38].

AT, PR, HZ, and LV can be coadministered together by some patients, and they are excreted mainly in the urine. To the best of our knowledge, no method has been reported for the simultaneous determination of the four drugs.

Green analytical chemistry (GAC), which is concerned with developing new methods that are sustainable and more environmentally friendly, has gained much interest among analytical chemists $[39,40]$. However, the challenge is to achieve a compromise between increasing the quality of the developed methods and improving the method greenness $[39,41]$. UV-Vis spectroscopy is considered a greener analytical technique when compared to HPLC. UV-Vis spectroscopy is a fast technique that consumes low solvent volumes, thus reducing the amount of generated waste. In addition, this technique is cost-effective and does not need expensive solvents or sophisticated instruments [42, 43]. However, the major challenge when using UV-Vis spectroscopy is the analysis of multicomponent mixtures, especially when the analytes spectra are strongly overlapped $[42,44]$. To overcome this challenge, the author proposed the use of nonconventional spectrophotometric technique, namely, extended derivative ratio (EDR). In addition, the use of multivariate calibration helped in the mathematical resolution of the multicomponent mixture.

Therefore, this work aimed to develop green, cost-effective, and precise methods for the analysis of AT, PR, HZ, and LV. Two methods including a nonconventional univariate method (i.e., extended derivative ratio (EDR)) and a 
multivariate method (i.e., multivariate curve resolution-alternating least squares (MCR-ALS)) were developed and validated and then successfully applied for analyzing the four analytes in different pharmaceutical dosage forms, spiked and real human urine. In addition, the method greenness was assessed using the National Environmental Methods Index (NEMI) $[45,46]$ and the analytical Eco-Scale [47].

\subsection{Theoretical Background}

1.1.1. Extended Derivative Ratio Technique (EDR). Let's consider mixture $M$ composed of four compounds ( $W, X, Y$, and $Z$ ). Once Beer's law is obeyed over the whole wavelength range, the absorption spectrum of $M$ will be equal to the sum of the individual spectra of the four analytes (i.e., the additive property of Beer's law). It can be defined by the following equation:

$$
A_{M \lambda_{i}}=\varepsilon_{W \lambda_{i}} C_{W}+\varepsilon_{X \lambda_{i}} C_{X}+\varepsilon_{Y \lambda_{i}} C_{Y}+\varepsilon_{Z \lambda_{i}} C_{Z}
$$

where $A_{M \lambda_{i}}$ is the absorbance of $M$ at wavelength $\lambda_{i}, \varepsilon_{W \lambda_{i}}$, $\varepsilon_{X \lambda_{i}}, \varepsilon_{Y \lambda_{i}}$ and $\varepsilon_{Z \lambda_{i}}$ are the molar absorptivity of compounds $W, X, Y$, and $Z$ at wavelength $\lambda_{i}$ and $C_{W}, C_{X}, C_{Y}$, and $C_{Z}$ are the concentrations of $W, X, Y$, and $Z$, respectively.

For compound $W$ determination, a mixture $\left(m_{1}\right)$ containing all other three compounds $(X, Y$, and $Z)$ except compound $W$ is scanned and it can be represented by the following equation:

$$
A^{\prime}{ }_{m 1 \lambda_{i}}=\varepsilon_{X \lambda_{i}} C^{\circ} \mathrm{X}+\varepsilon_{Y \lambda_{i}} C^{\circ}{ }_{\mathrm{Y}}+\varepsilon_{Z \lambda_{i}} C^{\circ} \mathrm{Z}
$$

For both equations (1) and (2) the optical path is considered to be $1 \mathrm{~cm}$.

Dividing the mixture spectrum $M$ by $m_{1}$ will result in the following ratio spectrum:

$$
\begin{aligned}
\frac{A_{M \lambda_{i}}}{A^{\prime}{ }_{m 1 \lambda_{i}}}= & \frac{\varepsilon_{W \lambda_{i}} C_{W}+\varepsilon_{X \lambda_{i}} C_{X}+\varepsilon_{Y \lambda_{i}} C_{Y}+\varepsilon_{Z \lambda_{i}} C_{Z}}{\varepsilon_{X \lambda_{i}} C^{\circ}{ }_{X}+\varepsilon_{Y \lambda_{i}} C^{\circ}+\varepsilon_{Z \lambda_{i}} C^{\circ}{ }_{Z}} \\
= & \frac{\varepsilon_{W \lambda_{i}} C_{W}}{\varepsilon_{X \lambda_{i}} C^{\circ}{ }_{X}+\varepsilon_{Y \lambda_{i}} C^{\circ}+\varepsilon_{Z \lambda_{i}} C^{\circ}{ }_{Z}} \\
& +\frac{\varepsilon_{X \lambda_{i}} C_{X}+\varepsilon_{Y \lambda_{i}} C_{Y}+\varepsilon_{Z \lambda_{i}} C_{Z}}{\varepsilon_{X \lambda_{i}} C^{\circ}{ }_{X}+\varepsilon_{Y \lambda_{i}} C^{\circ}{ }_{Y}+\varepsilon_{Z \lambda_{i}} C^{\circ}{ }_{Z}} \\
= & \frac{\varepsilon_{W \lambda_{i}} C_{W}}{\varepsilon_{X \lambda_{i}} C^{\circ}{ }_{X}+\varepsilon_{Y \lambda_{i}} C^{\circ}+\varepsilon_{Z}{ }_{Z \lambda_{i}} C^{\circ} \mathrm{Z}}+\mathrm{K},
\end{aligned}
$$

where $\mathrm{K}$ is constant. follows:

The derivative ratio spectra can be represented as

$$
\begin{aligned}
\frac{d}{d \lambda}\left[\frac{A_{M \lambda_{i}}}{A^{6}{ }_{m 1 \lambda_{i}}}\right] & =\frac{d}{d \lambda}\left[\frac{\varepsilon_{W \lambda_{i}} C_{W}}{\varepsilon_{X \lambda_{i}} C^{\circ}{ }_{\mathrm{X}}+\varepsilon_{Y \lambda_{i}} C^{\circ}{ }^{\circ}+\varepsilon_{Z \lambda_{i}} C^{\circ}{ }_{\mathrm{Z}}}\right] \\
& =\frac{d}{d \lambda}\left[\frac{\varepsilon_{W \lambda_{i}}}{\varepsilon_{X \lambda_{i}} C^{\circ}{ }_{\mathrm{X}}+\varepsilon_{Y \lambda_{i}} C^{\circ}{ }_{\mathrm{Y}}+\varepsilon_{Z \lambda_{i}} C^{\circ}{ }_{\mathrm{Z}}}\right] C_{W}
\end{aligned}
$$

Equation (4) indicates that the derivative ratio spectrum amplitude is dependent and directly proportional to the concentration of the compound $W$. Therefore a calibration curve can be drawn by dividing the spectra of various concentrations of a pure compound $W$ by the ternary mixture of the other three compounds, and a regression equation can be obtained. Similarly, the other three compounds can be determined using the same procedure as for compound $W$.

1.1.2. Multivariate Curve Resolution-Alternating Least Squares (MCR-ALS). MCR is a soft-modeling algorithm that can extract relevant information of the pure components in multicomponent systems. It can be performed through the bilinear decomposition of the data matrix $D$ as follows:

$$
D=C S^{T}+E,
$$

where $C$ and $S^{T}$ are the pure concentration and spectral profiles [48]. $E$ is the residuals matrix of the data not explained by the bilinear model. The $C$ and $S^{T}$ profiles can be optimized iteratively using Alternating Least Squares (ALS) until a certain convergence criterion is achieved. The initial estimates of the components' spectra were used to start the optimization process, and simple-to-use interactive selfmodeling mixture analysis (SIMPLISMA) [49] was employed. Specific constraints such as nonnegativity, closure, unimodality, and correlation constraints $[50,51]$ can be applied during the optimization process. In the presented work, nonnegativity spectra constraint, nonnegativity concentration constraint, and correlation constraint were applied. The latter constraint enhances building a calibration model that allows the quantitative analysis of components in the presence of unknown interferences $[50,52]$.

The MCR-ALS model's consistency and reliability can be measured using the percentage of lack of fit (Equation (6)) and the percentage of total explained variance (Equation (7)). The following equations help to calculate the two parameters:

$$
\begin{aligned}
\text { lack of fit }(\%) & =100 \sqrt{\frac{\sum_{i . j} e_{i j}^{2}}{\sum_{i . j} d_{i j}^{2}},} \\
S^{2} & =100 \sqrt{\frac{\sum_{i . j} d_{i j}^{2}-\sum_{i . j} e_{i j}^{2}}{\sum_{i . j} d_{i j}^{2}}},
\end{aligned}
$$

where $d_{i j}$ is an element of the data matrix $D$ and $e_{i j}$ is the associated residual (the difference between experimental data input and model reproduced data).

(1) Validation of the Model. The performance of the developed model will be evaluated, employing a data set composed of 7 mixtures used as an external validation set. Different figures of merit were calculated to evaluate the obtained results according to the following equations [50]: 
Root mean square error of prediction (RMSEP),

$$
\text { RMSEP }=\sqrt{\frac{\sum_{i=1}^{n}\left(c_{i}-\widehat{c}_{i}\right)^{2}}{n}},
$$

Bias,

$$
\text { bias }=\frac{\sum_{i=1}^{n}\left(c_{i}-\widehat{c}_{i}\right)}{n}
$$

Standard error of prediction (SEP),

$$
\mathrm{SEP}=\sqrt{\frac{\sum_{i=1}^{n}\left(c_{i}-\widehat{c}_{i}-\text { bias }\right)^{2}}{n-1}} .
$$

Relative percentage error in the concentration predictions (RE \%),

$$
\operatorname{RE}(\%)=100 \sqrt{\frac{\sum_{i=1}^{n}\left(c_{i}-\widehat{c}_{i}\right)^{2}}{\sum_{i=1}^{n} c_{i}^{2}}},
$$

where $c_{i}$ and $\widehat{c}_{i}$ are the known and predicted analyte concentration in sample $i$, respectively, and $n$ is the total number of validation samples.

Furthermore, a linear regression fit was performed between the known and predicted concentrations, and slope, intercept, and determination coefficients were calculated.

\section{Material and Methods}

2.1. Instrumentation and Software. Shimadzu UV-1800 double-beam spectrophotometer (Tokyo, Japan) with $1 \mathrm{~cm}$ quartz cells was used for data acquisition. Scans were recorded in the wavelength range of $200-330 \mathrm{~nm}$ at $0.2 \mathrm{~nm}$ intervals. Spectra were acquired by Shimadzu UV-Probe version 2.62. The MCR model was developed using MCRALS GUI 2.0 software for use with Matlab 2015a [53]. The software is freely available at http://www.mcrals.info.

2.2. Chemicals and Reagents. Atenolol (CAS no. 29122-68-7; 98\% minimum purity), paracetamol (CAS no. 103-90-2; $98 \%$ minimum purity), and hydrochlorothiazide (CAS no. 58-93-5; 98\% minimum purity) were purchased from Sigma-Aldrich (Steinheim, Germany). Levofloxacin hemihydrate (CAS no. 138199-71-0; 99\% minimum purity) was purchased from Santa Cruz Biotechnology Inc. (Santa Cruz, Canada). Helix pomatia $\beta$-glucuronidase enzyme used for hydrolysis was obtained from Sigma-Aldrich (St. Louis, USA).

Ethanol (LiChrosolv ${ }^{\circledR}$, HPLC grade) was obtained from Merck (Darmstadt, Germany). Ultrapure water (18.2 M $\Omega$ ) was obtained by Pure Lab Ultra water system (ELGA, High Wycombe, United Kingdom) and used for all sample preparation.

This study was approved by the Research and Ethics Committee of the College of Clinical Pharmacy, Imam Abdulrahman Bin Faisal University, Saudi Arabia. Upon receiving informed written consent, blank urine samples were collected from three healthy volunteers (23-25 years old) and were kept at $-20^{\circ} \mathrm{C}$.
Commercial pharmaceutical dosage forms of the studied drugs were purchased from the local market and they were as follows:

(i) Tenormin ${ }^{\circledR}$ tablets (batch \# PF742) produced by AstraZeneca UK Limited, United Kingdom and labeled to contain $100 \mathrm{mg}$ AT per tablet.

(ii) Panadrex ${ }^{\circledR}$ tablets (batch \# JT377) produced by Kuwait Saudi Pharmaceutical Industries Co, Kuwait and labeled to contain $500 \mathrm{mg}$ PR per tablet.

(iii) HCT Georetic $25^{\circledR}$ tablets (batch \# 1832207) produced by Marcyrl Pharmaceutical Industries, Egypt and labeled to contain $25 \mathrm{mg} \mathrm{HZ}$ per tablet.

(iv) Tavanic ${ }^{\circledR}$ tablets (batch \# 7PK7A) produced by Sanofi Winthrop Industries, France and labeled to contain $500 \mathrm{mg} \mathrm{LV}$ per tablet.

\subsection{Procedures}

2.3.1. Standard Solutions. Stock solutions were prepared by dissolving $10 \mathrm{mg}$ of AT, PR, HZ, and LV separately in $10 \mathrm{~mL}$ ethanol and were used as stock standard solutions for the EDR and MCR-ALS methods. All solutions were stored at $4^{\circ} \mathrm{C}$ and were stable for at least three months. Working solutions were obtained by appropriate dilutions using ultrapure water to reach the calibration range of each method.

2.3.2. Spectroscopic Characteristics. The UV spectra of solutions comprising $10 \mu \mathrm{g} \mathrm{mL}^{-1}$ of AT and $5 \mu \mathrm{g} \mathrm{mL}^{-1}$ of $\mathrm{PR}$, $\mathrm{HZ}$ and LV were analyzed separately over the wavelength range of $200-330 \mathrm{~nm}$.

2.3.3. EDR Method. Appropriate volumes of each stock standard solution of AT, PR, HZ and LV were transferred into four different sets of $10-\mathrm{mL}$ volumetric flasks and diluted with ultrapure water to reach the calibration range of 5-40, 1-25, 1-15, and 1-15 $\mu \mathrm{g} \mathrm{mL}^{-1}$ for AT, PR, HZ, and LV, respectively. The absorption spectra were measured over the range of 200 to $330 \mathrm{~nm}$ using ultrapure water as blank.

(1) Determination of AT. A mixture composed of 7, 2, and $4 \mu \mathrm{g} \mathrm{mL}^{-1}$ of $\mathrm{PR}, \mathrm{HZ}$, and $\mathrm{LV}$, respectively, was scanned against ultrapure water as blank and spectra were stored (AT divisor). The UV spectra of working standard solutions of AT were divided by the stored divisor, and the second derivative of the resulting ratio spectra was calculated employing $\Delta \lambda=4 \mathrm{~nm}$ and 10 as a scaling factor. The amplitudes at $281.6 \mathrm{~nm}$ were directly proportional to AT concentration. The calibration curve was obtained and the corresponding regression equation was calculated.

(2) Determination of PR. A mixture composed of 15, 3, and $5 \mu \mathrm{g} \mathrm{mL}^{-1}$ of $\mathrm{AT}, \mathrm{HZ}$, and $\mathrm{LV}$, respectively, was scanned against ultrapure water as blank and spectra were stored (PR divisor). The UV spectra of working standard solutions of PR were divided by the stored divisor, and the first derivative of the resulting ratio spectra was calculated employing 
$\Delta \lambda=4 \mathrm{~nm}$ and 10 as a scaling factor. The amplitudes at $237.6 \mathrm{~nm}$ were directly proportional to PR concentration. The calibration curve was obtained, and the corresponding regression equation was calculated.

(3) Determination of HZ. A mixture composed of 15, 10, and $5 \mu \mathrm{g} \mathrm{mL}^{-1}$ of $\mathrm{AT}, \mathrm{PR}$, and $\mathrm{LV}$, respectively, was scanned against ultrapure water as blank and spectra were stored ( $\mathrm{HZ}$ divisor). The UV spectra of working standard solutions of $\mathrm{HZ}$ were divided by the stored divisor, and the first derivative of the resulting ratio spectra was calculated using $\Delta \lambda=2 \mathrm{~nm}$ and 10 as a scaling factor. The amplitudes at $279.2 \mathrm{~nm}$ were directly proportional to $\mathrm{HZ}$ concentration. The calibration curve was obtained, and the corresponding regression equation was calculated.

(4) Determination of $L V$. A mixture composed of 15,7 , and $2 \mu \mathrm{g} \mathrm{mL}^{-1}$ of $\mathrm{AT}, \mathrm{PR}$, and $\mathrm{HZ}$, respectively, was scanned against ultrapure water as blank and spectra were stored (LV divisor). The UV spectra of working standard solutions of LV were divided by the stored divisor, and the second derivative of the resulting ratio spectra was calculated employing $\Delta \lambda=4 \mathrm{~nm}$ and 10 as a scaling factor. The amplitudes at $282.8 \mathrm{~nm}$ were directly proportional to the concentration of LV. The calibration curve was obtained, and the corresponding regression equation was calculated.

2.3.4. MCR-ALS Method. Calibration and validation sets composed of 25 samples were constructed using a five-level four-factors design [54], in which five different concentration levels of AT, PR, HZ, and LV were introduced. The levels ranges were $5-25,1-10,1-10$, and $1-7 \mu \mathrm{g} \mathrm{mL}^{-1}$ for AT, PR, HZ, and LV, respectively. The UV spectra of all samples were scanned from 220 to $330 \mathrm{~nm}$ at $0.2 \mathrm{~nm}$ intervals. Eighteen samples were used to build the calibration model, while seven samples, randomly selected, were used for external validation. The absorption spectra were exported into Matlab to build the MCR-ALS calibration model using MCR-ALS GUI 2.0 software [53]. Fast nonnegativity least squares (for spectral and concentration profiles) and correlation constraints were employed.

\subsection{Sample Preparation}

2.4.1. Analysis of Pharmaceutical Preparations. Ten tablets of each commercial formulation were weighed and pulverized. A portion equivalent to $100.0 \mathrm{mg}$ of AT, PR, HZ, and LV were accurately added to a $100 \mathrm{~mL}$ conical flask and sonicated with $50 \mathrm{~mL}$ ethanol for $30 \mathrm{~min}$. The solution was filtered into a $100 \mathrm{~mL}$ volumetric flask and completed to mark with ethanol. The procedures for EDR and MCR-ALS methods were followed as detailed under Sections 2.3.3 and 2.3.4, respectively.

2.4.2. Analysis of Spiked and Real Human Urine Samples. All urine samples were syringe filtered through $0.45 \mu \mathrm{m}$ nylon filters. Aliquots of $100 \mu \mathrm{L}$ of blank urine were transferred into a set of $10 \mathrm{~mL}$ volumetric flasks. Different volumes of the stock standard solutions of AT, PR, HZ, and LV were added, vortex mixed, and the volume was completed to mark with ultrapure water. The procedures for EDR and MCR-ALS methods were followed as detailed under Sections 2.3.3 and 2.3.4, respectively. Analytes concentrations were calculated using the corresponding regression equations.

For method application in the analysis of real urine samples: (A) urine was collected $0-12 \mathrm{~h}$ from a healthy volunteer after the administration of a single oral dose of $500 \mathrm{mg}$ PR, and (B) urine was collected $0-12 \mathrm{~h}$ from a healthy volunteer after the administration of $500 \mathrm{mg}$ of LV. The collected urine volumes were accurately measured. A $100 \mu \mathrm{L}$ aliquot was diluted into $10 \mathrm{~mL}$ using ultrapure water and used for the direct determination of PR and LV.

\section{Results and Discussion}

Figure 2 shows the zero-order absorption spectra of AT, PR, $\mathrm{HZ}$, and LV. There is a severe overlap between the absorption bands of the four analytes over the whole wavelength range $(200-330 \mathrm{~nm})$. Thus, the simultaneous determination of these drugs is hindered using conventional calibration procedures without prior separation. Therefore, simple, reliable, and precise nonconventional univariate and multivariate chemometrics-assisted spectrophotometric methods were proposed for the simultaneous analysis of AT, $\mathrm{PR}, \mathrm{HZ}$, and LV in pharmaceutical dosage forms, spiked and real human urine samples. Furthermore, the developed methods' performance was evaluated and statistically compared with published methods $[3,16,28,34]$.

\subsection{EDR Method}

3.1.1. Selection of Divisors and Derivative Parameters. The severe spectral overlap of the analytes of interest demonstrates the resolving power of the proposed method. Each analyte can be determined by using a divisor mixture composed of the other three analytes.

Six synthetic mixtures were prepared containing different concentration ratios of $\mathrm{AT}, \mathrm{PR}, \mathrm{HZ}$, and $\mathrm{LV}$ within their linear ranges. The zero-order absorption spectra of these solutions were recorded and stored.

For determination of AT, the stored spectra of standard solutions containing AT, PR, HZ, and LV were divided by the stored AT divisor; then the second derivative of the obtained ratio spectra $\left({ }^{2} \mathrm{DD}\right)$ was calculated using $\Delta \lambda=4 \mathrm{~nm}$ and scaling factor 10 (Figure 3(a)). For the determination of AT, a reproducible amplitude was selected from the obtained derivative spectra. The calculated amplitude at $281.6 \mathrm{~nm}$ was found to be proportional to the concentration of AT.

On the other hand, for PR determination, the same procedures were followed and the ratio spectra were obtained as described above using PR divisor. Then, the first derivative of the ratio spectra $\left({ }^{1} \mathrm{DD}\right)$ was calculated employing $\Delta \lambda=4 \mathrm{~nm}$ and 10 as a scaling factor (Figure $3(\mathrm{~b})$ ). 


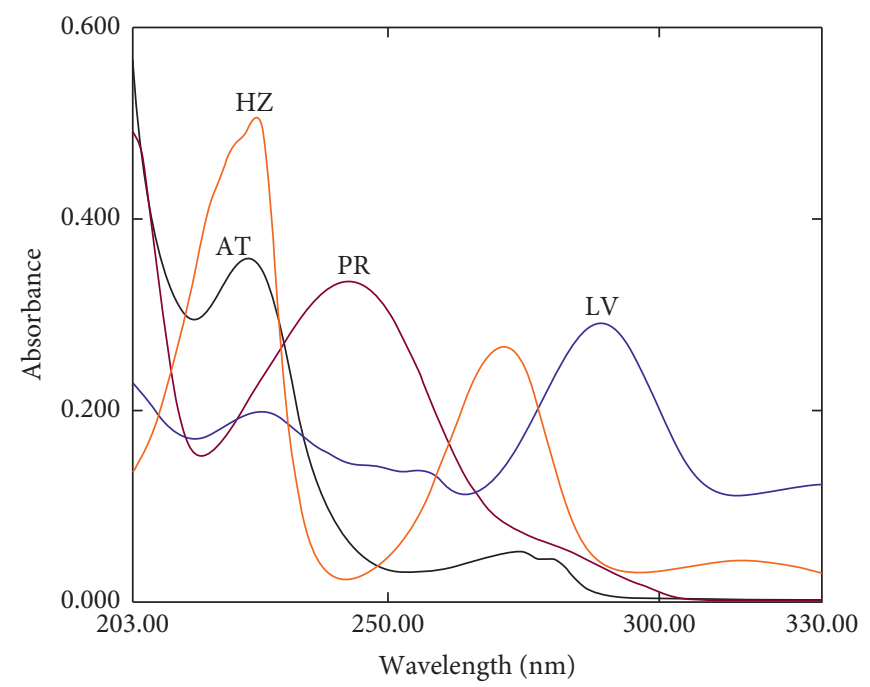

FIgURe 2: Zero-order absorption spectra of $10 \mu \mathrm{g} \mathrm{ml}^{-1}$ atenolol (AT), $5 \mu \mathrm{g} \mathrm{ml}^{-1}$ paracetamol (PR), $10 \mu \mathrm{g} \mathrm{ml} \mathrm{l}^{-1}$ hydrochlorothiazide (HZ), and $5 \mu \mathrm{g} \mathrm{ml}^{-1}$ levofloxacin (LV).

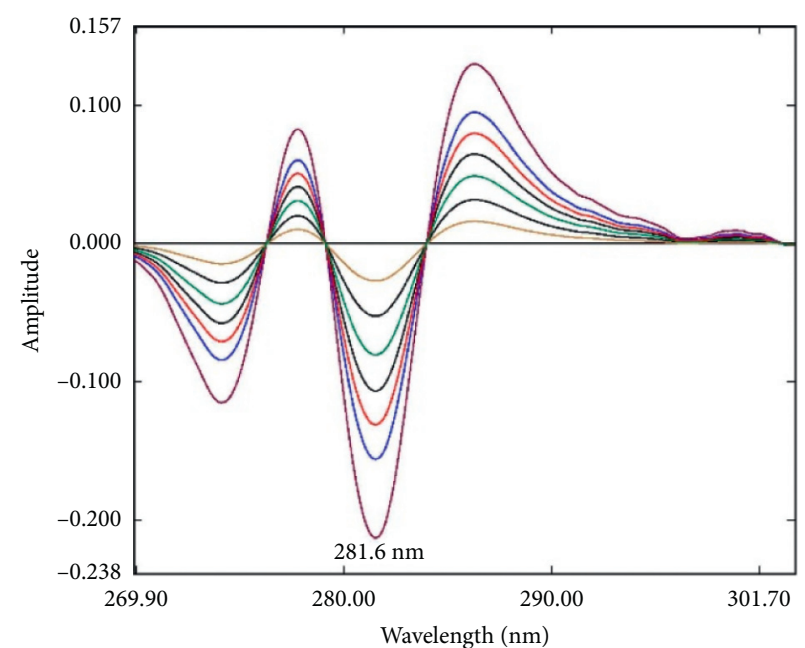

(a)

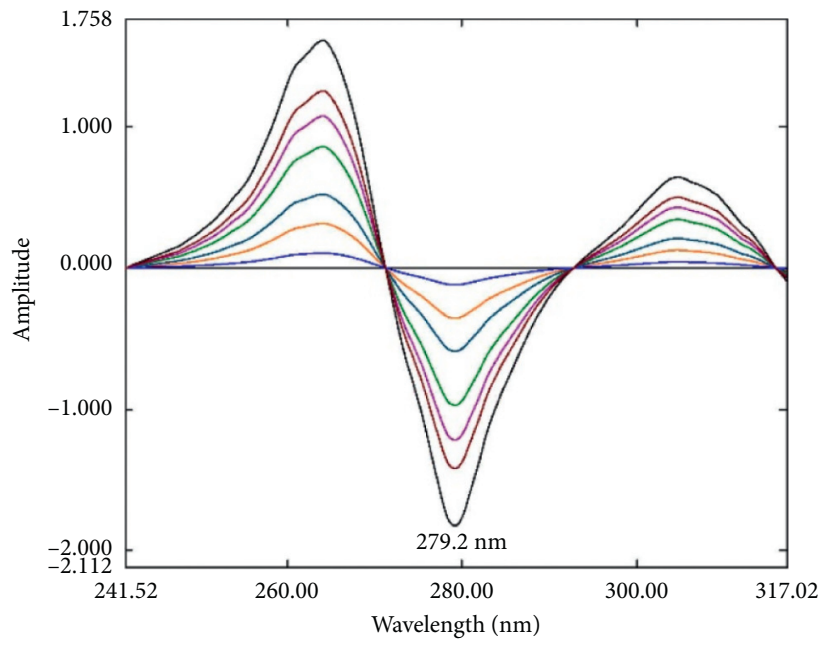

(c)

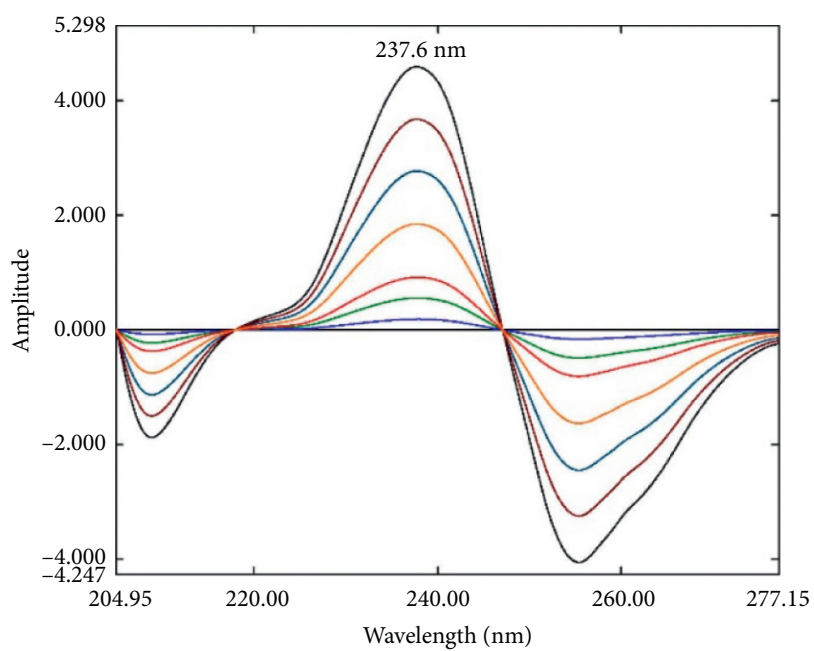

(b)

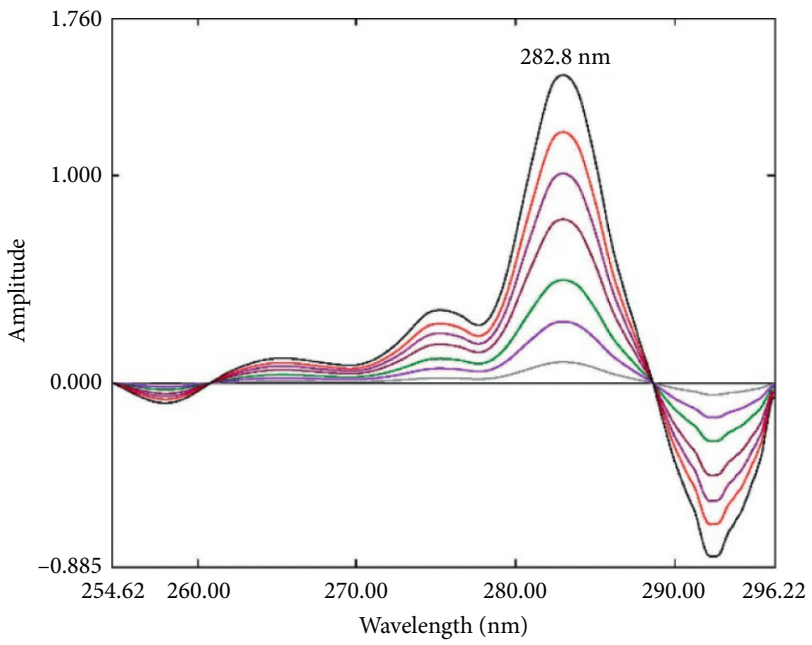

(d)

Figure 3: Overlay of the derivative ratio spectra obtained: (a) ${ }^{2} \mathrm{DD}$ of AT (5-40 $\left.\mu \mathrm{g} \mathrm{mL}^{-1}\right)$; (b) ${ }^{1} \mathrm{DD}$ of PR $\left(1-25 \mu \mathrm{g} \mathrm{mL} \mathrm{C}^{-1}\right)$; (c) ${ }^{1} \mathrm{DD}$ of $\mathrm{HZ}$ $\left(1-15 \mu \mathrm{g} \mathrm{mL}^{-1}\right)$; and (d) ${ }^{2} \mathrm{DD}$ of LV $\left(1-15 \mu \mathrm{g} \mathrm{mL} \mathrm{L}^{-1}\right)$. 
The calculated amplitude at $237.6 \mathrm{~nm}$ was found to be proportional to the concentration of PR.

Moreover, $\mathrm{HZ}$ was determined using similar procedures using the $\mathrm{HZ}$ divisor, and the ${ }^{1} \mathrm{DD}$ was calculated employing $\Delta \lambda=2 \mathrm{~nm}$ and 10 as a scaling factor (Figure 3(c)). The amplitude at $279.2 \mathrm{~nm}$ was measured and found to be proportional to the concentration of HZ.

Furthermore, LV was determined by using LV divisor and the ${ }^{2} \mathrm{DD}$ was calculated using $\Delta \lambda=4 \mathrm{~nm}$ and scaling factor of 10 (Figure 3(d)). The amplitude at $282.8 \mathrm{~nm}$ was calculated and found to be proportional to LV concentration.

The main parameters affecting the developed method performance were optimized for reliable and accurate determination of the analytes of interest. This included optimization of the divisor selection, which is a vital step in the proposed technique. The concentration of each analyte in the divisor was selected in a way that absorbances are low but meanwhile spectral features are evident [55]. Different mixtures were prepared and tested as divisor and the optimum one was selected. First and second derivatives of the ratio spectra were calculated and tested. The first derivative provided reliable and accurate results in case of PR and HZ. However, ${ }^{2} \mathrm{DD}$ was preferred than ${ }^{1} \mathrm{DD}$ in case of AT and LV because it provided better spectral resolution and more accurate and precise results. Moreover, the effect of the $\Delta \lambda$ for ${ }^{1} \mathrm{DD}$ and ${ }^{2} \mathrm{DD}$ was optimized and the best results were obtained using $\Delta \lambda=2$ for HZ and $\Delta \lambda=4$ for AT, PR, and LV. Furthermore, the scaling factor was optimized and a factor of 10 was found suitable for all analytes.

3.1.2. Method Validation. Method validation was performed according to the International Conference on Harmonization (ICH) recommendations [56].

(1) Linearity. Seven concentrations were used in the concentration range of $5-40,1-25,1-15$, and $1-15 \mu \mathrm{g} \mathrm{m}^{-1}$ of AT, PR, HZ, and LV, respectively. The developed method showed a high correlation coefficient $(r \geq 0.9994)$ and intercept value that was not statistically $(p<0.05)$ different from zero. Regression parameters are shown in Table 1.

(2) Detection and Quantitation Limits. Limit of detection (LOD) was calculated according to ICH as $3.3(\sigma / S)$ and limit of quantification was calculated as $10(\sigma / S)$, where " $\sigma$ " is the standard deviation of the intercept and " $S$ " is the slope of the calibration curve (Table 1).

(3) Accuracy and Precision. Method accuracy was evaluated using three different concentrations of each drug analyzed in triplicate and percentage recovery of each analyte was calculated. Precision was evaluated by analyzing three different concentrations of each drug in triplicate within the same day (Intraday) and for three consecutive days (Interday) and relative standard deviation (\%RSD) was calculated. The samples were analyzed according to the procedures under "2.3.3". The results summed in Table 1 shows excellent recoveries and \% RSD lower than 1.26 indicating the good accuracy and precision of the proposed method.

(4) Selectivity. Method selectivity was investigated using several laboratory synthetic mixtures comprising the four analytes in different concentration ratios within the linearity range. The results shown in Table 2 indicate the high selectivity of the EDR method.

(5) Statistical Analysis. The obtained results of the developed methods were compared with the published methods for the determination of AT [3], PR [16], HZ [28], and LV [34]. The results obtained in Table 3 revealed no significant difference between the proposed and the published methods with respect to accuracy and precision.

\subsection{Multivariate Curve Resolution-Alternating Least} Squares. The severe spectral overlap between the four analytes and the presence of unknown sample interferences in the urine matrix necessitate the use of multivariate calibration models to resolve such kind of mixtures. First-order multivariate calibration methods may be a good choice in such case only if the interfering background is well represented in the calibration phase. However, if such interferences are not represented in the calibration, first-order methods may not be a good choice. In such instances, second-order multivariate calibration models may work better due to their good prediction ability even in the presence of unknown interferences [57]. In this work, MCRALS model was developed for the determination of the four analytes of interest in pharmaceutical dosage forms and spiked human urine samples without including urine in the calibration samples.

3.2.1. Calibration Set. Multilevel multifactor experimental design was employed to construct 25 mixtures of the four analytes thus providing mutual orthogonal factors [54]. Five different concentration levels, within the calibration range, were used for each analyte. A total of 18 mixtures were used to build the calibration model and 7 mixtures were utilized as an external validation set as shown in Table 4.

3.2.2. Selection of the Wavelength Range. The quality of multivariate calibration relies on the wavelength range selected to build up the calibration model. Therefore, the data in the region $200-220 \mathrm{~nm}$ were discarded due to noise. Moreover, the band of $290-330 \mathrm{~nm}$ was excluded as well because AT had nonsignificant absorption in this region. Thus, the region of $220-290 \mathrm{~nm}$ with $0.4 \mathrm{~nm}$ interval was used in the developed MCR-ALS method.

3.2.3. Developing the MCR-ALS Model. No data preprocessing was conducted on the calibration matrix while developing the MCR-ALS model. To obtain a reasonable resolution by MCR-ALS model, initial estimation of the pure spectra of the target analytes was conducted. Five components were found to be responsible for the variations in 
TABLE 1: Characteristic validation parameters of the proposed EDR method for the determination of AT, PR, HZ, and LV.

\begin{tabular}{|c|c|c|c|c|}
\hline Parameters & $\mathrm{AT}$ & $\mathrm{PR}$ & $\mathrm{HZ}$ & LV \\
\hline Calibration range $\left(\mu \mathrm{g} \mathrm{mL}^{-1}\right)$ & $5-40$ & $1-25$ & $1-15$ & $1-15$ \\
\hline \multicolumn{5}{|l|}{ Regression equation: } \\
\hline Slope $(b)$ & 0.0053 & 0.1830 & 0.1211 & 0.0998 \\
\hline Intercept $(a)$ & $-1.43 \times 10^{-4}$ & $-3.23 \times 10^{-4}$ & $-6.10 \times 10^{-3}$ & $-1.37 \times 10^{-3}$ \\
\hline Correlation coefficient $\left(r^{2}\right)$ & 0.9995 & 0.9998 & 0.9994 & 0.9996 \\
\hline Standard deviation of slope $\left(S_{b}\right)$ & $5.19 \times 10^{-5}$ & $1.24 \times 10^{-3}$ & $1.32 \times 10^{-3}$ & $8.50 \times 10^{-4}$ \\
\hline Standard deviation of intercept $\left(S_{a}\right)$ & $1.22 \times 10^{-3}$ & $1.75 \times 10^{-2}$ & $1.18 \times 10^{-2}$ & $7.66 \times 10^{-3}$ \\
\hline $\operatorname{LOD}^{\mathrm{a}}\left(\mu \mathrm{g} \mathrm{mL}^{-1}\right)$ & 0.76 & 0.31 & 0.32 & 0.25 \\
\hline $\mathrm{LOQ}^{\mathrm{b}}\left(\mu \mathrm{g} \mathrm{mL}^{-1}\right)$ & 2.31 & 0.95 & 0.98 & 0.77 \\
\hline Accuracy $\left(\right.$ mean $\left.\pm S^{c}\right)$ & $99.82 \pm 0.88$ & $99.93 \pm 0.85$ & $99.98 \pm 0.69$ & $100.26 \pm 0.77$ \\
\hline \multicolumn{5}{|l|}{ Precision: } \\
\hline Intraday $\left(\% \mathrm{RSD}^{\mathrm{d}}\right)$ & 0.70 & 0.66 & 0.93 & 0.98 \\
\hline Interday $\left(\% \mathrm{RSD}^{\mathrm{e}}\right)$ & 1.26 & 0.88 & 0.90 & 0.94 \\
\hline
\end{tabular}

${ }^{\mathrm{a}}$ Limit of detection. ${ }^{\mathrm{b}}$ Limit of quantification. ${ }^{\mathrm{c}}$ Standard deviation of three different concentrations each analyzed in triplicate. ${ }^{\mathrm{d}}$ Relative standard deviation of three different concentrations analyzed in triplicate within the same day. ${ }^{e}$ Relative standard deviation of three different concentrations analyzed in triplicate on three consecutive days.

TABle 2: Determination of AT, PR, HZ, and LV in synthetic mixtures using the proposed EDR method.

\begin{tabular}{|c|c|c|c|c|c|c|c|c|}
\hline \multirow{2}{*}{ Mix. No. } & \multicolumn{4}{|c|}{ Conc. $\left(\mu \mathrm{g} \mathrm{mL}^{-1}\right)$} & \multicolumn{4}{|c|}{ \% Recovery } \\
\hline & $\mathrm{AT}$ & $\mathrm{PR}$ & $\mathrm{HZ}$ & LV & $\mathrm{AT}$ & PR & $\mathrm{HZ}$ & LV \\
\hline 1 & 15 & 10 & 3 & 6 & 98.15 & 99.70 & 100.70 & 101.5 \\
\hline 2 & 30 & 2 & 5 & 5 & 97.85 & 99.15 & 99.70 & 99.40 \\
\hline 3 & 25 & 6 & 8 & 4 & 100.20 & 101.20 & 98.45 & 100.00 \\
\hline 4 & 25 & 5 & 7 & 4 & 99.56 & 100.91 & 101.62 & 100.25 \\
\hline 5 & 10 & 1 & 4 & 1 & 102.11 & 98.70 & 101.90 & 99.10 \\
\hline 6 & 15 & 4 & 5 & 3 & 98.40 & 100.00 & 99.80 & 99.80 \\
\hline Mean & & & & & 99.38 & 99.94 & 100.36 & 100.01 \\
\hline$\pm \mathrm{SD}$ & & & & & 1.61 & 0.97 & 1.30 & 0.84 \\
\hline
\end{tabular}

TABLE 3: Statistical comparison of the proposed EDR method with published methods for the determination of AT, PR, HZ, and LV.

\begin{tabular}{lcccccccc}
\hline & \multicolumn{2}{c}{ AT } & \multicolumn{2}{c}{ PR } & \multicolumn{2}{c}{ HZ } & LV \\
& EDR & Published method [3] & EDR & Published method [16] & EDR & Published method [28] & EDR & Published method [34] \\
\hline Mean & 99.77 & 100.05 & 101.04 & 100.11 & 101.07 & 100.30 & 99.69 & 100.15 \\
$\pm \mathrm{SD}$ & 1.10 & 1.06 & 1.16 & 1.05 & 0.71 & 0.96 & 1.22 & 1.12 \\
$\mathrm{n}$ & 3 & 3 & 3 & 3 & 3 & 3 & 3 & 1.63 \\
$t^{\mathrm{a}}$ & 0.23 & & 1.32 & & 1.08 & & 1.19 \\
$F^{\mathrm{a}}$ & 1.08 & & 1.21 & & 1.86 & & 3 \\
\hline
\end{tabular}

${ }^{\mathrm{a}}$ Critical values of $t$ and $F$ are 4.30 and 19.00, respectively, at $(p=0.05)$.

different samples. Nonnegativity constraint (for spectral and concentration profiles) and correlation constraints were used in developing the model. The model resolved five species. The first four curves were very similar to AT, PR, $\mathrm{HZ}$, and LV spectra with a correlation coefficient $\left(r^{2}\right.$ $=0.9996,0.9998,0.9997$, and 09999, respectively) between the real and calculated AT, PR, HZ, and LV spectra. The fifth spectrum was estimated as the interfering urine matrix. The estimated spectral profiles are shown in Figure 4 . The resolved matrix for each analyte was used to find the concentration profiles of each analyte and satisfactory results were obtained with a low lack of fit (\% lof) of 0.1721 . The developed model captured $99.99 \%$ of variance in the analyzed spectra. Figure 5 shows the scatter plot of concentration values resolved by the MCR-ALS model versus the true concentration values. Good predictive ability of the model was obtained with determination coefficients of not less than 0.9998 for the four analytes. Table 5 shows the different figures of merit of the developed model.

3.2.4. Validation of the MCR-ALS Model. The developed model was applied on a series of external validation data set composed of 7 different synthetic mixtures within the calibration range of the analytes of interest (Table 4 ). The percent recoveries summarized in Table 6 show satisfactory results. To further validate the model, different figures of merit including RMSEP, SEP, RE\%, and $r^{2}$ were calculated for the external validation set. Satisfactory results were obtained as shown in Table 6. Moreover, accuracy, intraday and interday precision 
TABLE 4: The concentration matrix used for preparation of the calibration and validation sets for the MCR-ALS method.

\begin{tabular}{|c|c|c|c|c|}
\hline Mix. no. & $\mathrm{AT}$ & PR & $\mathrm{HZ}$ & LV \\
\hline 1 & 15 & 5.5 & 5.5 & 4 \\
\hline 2 & 15 & 1 & 1 & 7 \\
\hline $3^{*}$ & 5 & 1 & 10 & 2.5 \\
\hline $4^{*}$ & 5 & 10 & 3.5 & 7 \\
\hline 5 & 25 & 3.5 & 10 & 4 \\
\hline 6 & 10 & 10 & 5.5 & 2.5 \\
\hline 7 & 25 & 5.5 & 3.5 & 2.5 \\
\hline 8 & 15 & 3.5 & 3.5 & 5.5 \\
\hline $9^{*}$ & 10 & 3.5 & 8 & 7 \\
\hline 10 & 10 & 8 & 10 & 5.5 \\
\hline 11 & 20 & 10 & 8 & 4 \\
\hline 12 & 25 & 8 & 5.5 & 7 \\
\hline 13 & 20 & 5.5 & 10 & 7 \\
\hline 14 & 15 & 10 & 10 & 1 \\
\hline $15^{*}$ & 25 & 10 & 1 & 5.5 \\
\hline 16 & 25 & 1 & 8 & 1 \\
\hline 17 & 5 & 8 & 1 & 4 \\
\hline $18^{*}$ & 20 & 1 & 5.5 & 5.5 \\
\hline 19 & 5 & 5.5 & 8 & 5.5 \\
\hline $20^{*}$ & 15 & 8 & 8 & 2.5 \\
\hline 21 & 20 & 8 & 3.5 & 1 \\
\hline 22 & 20 & 3.5 & 1 & 2.5 \\
\hline $23^{*}$ & 10 & 1 & 3.5 & 4 \\
\hline 24 & 5 & 3.5 & 5.5 & 1 \\
\hline 25 & 10 & 5.5 & 1 & 1 \\
\hline
\end{tabular}

* Mixtures used as external validation set.

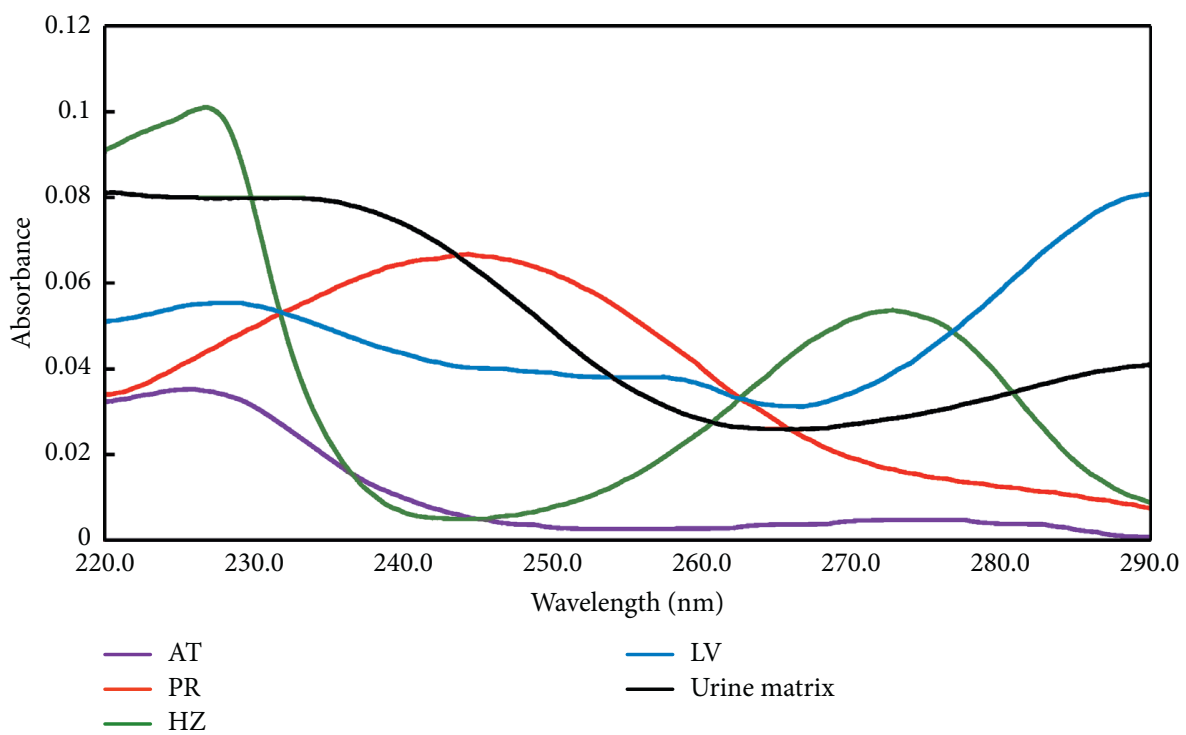

FIgURE 4: MCR-ALS resolved spectral profiles of the four target analytes (AT, PR, HZ, and LV) and the interfering urine matrix.

were calculated for the external validation set to further evaluate the model. Satisfactory results were obtained in terms of accuracy and precision (Table 6).

\subsection{Analysis of Real Samples}

3.3.1. Analysis of Pharmaceutical Formulations. The developed methods were successfully used for the quantification of AT, PR, HZ, and LV in different pharmaceutical formulations and the results were statistically compared with the reported methods using paired $t$-test and $\mathrm{F}$ ratio at $95 \%$ confidence level. Satisfactory results were obtained showing no significant difference with the reported methods in terms of accuracy and precision (Table 7).

3.3.2. Analysis of Spiked and Real Human Urine Samples. EDR and MCR-ALS methods were successfully employed for the quantification of the four analytes of interest in 


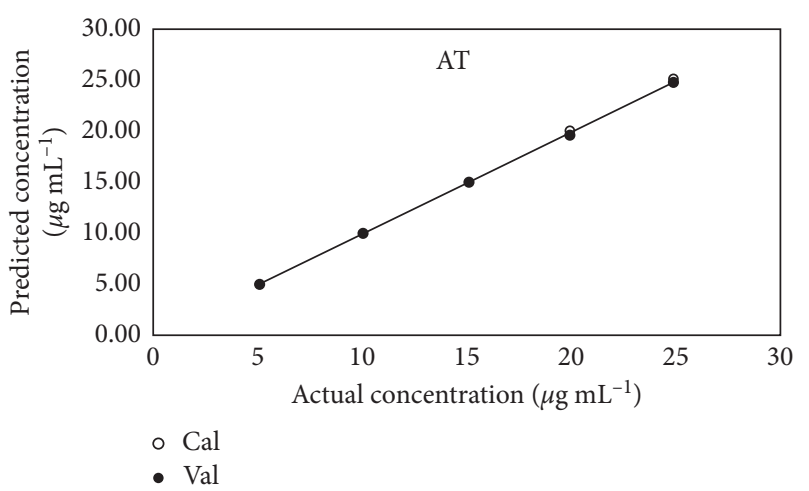

(a)

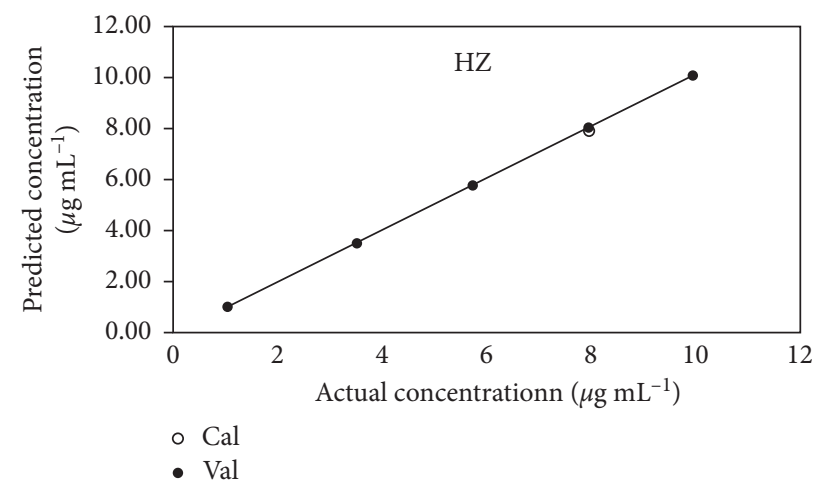

(c)

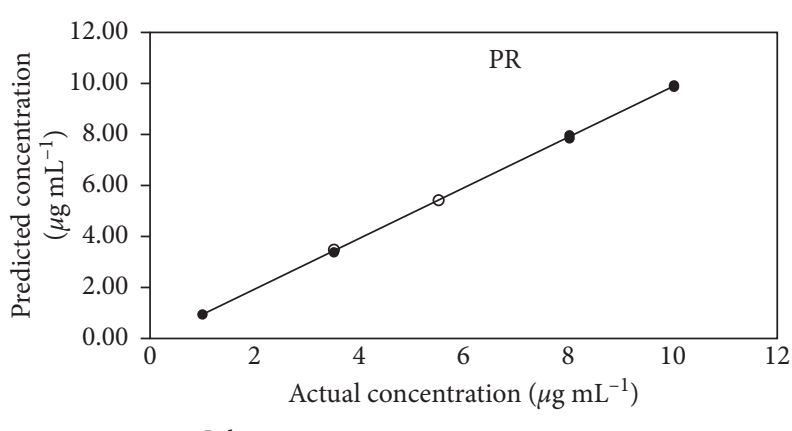

- Cal

- Val

(b)

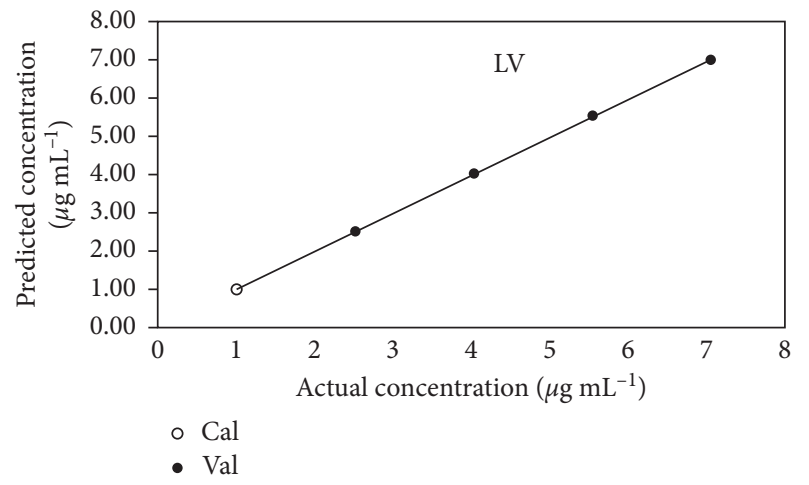

(d)

Figure 5: Scatter plot of actual drugs concentrations versus MCR-ALS predicted values of AT, PR, HZ, and LV.

TABLE 5: Figures of merit of the MCR-ALS model for the calibration set of AT, PR, HZ, and LV.

\begin{tabular}{lcccc}
\hline Parameters & AT & PR & HZ & LV \\
\hline Calibration range $\left(\mu \mathrm{g} \mathrm{mL} \mathrm{mL}^{-1}\right)$ & $5-25$ & $1-10$ & $1-10$ & $1-7$ \\
Slope & 0.9998 & 1.0000 & 1.0001 & 1.0014 \\
Standard error of slope & $3.28 \times 10^{-3}$ & $3.00 \times 10^{-3}$ & $2.80 \times 10^{-3}$ & $-8.88 \times 10^{-3}$ \\
Intercept & $3.27 \times 10^{-3}$ & $4.96 \times 10^{-4}$ & $-7.84 \times 10^{-5}$ & $-3.29 \times 10^{-3}$ \\
Standard error of intercept & $5.67 \times 10^{-2}$ & $1.95 \times 10^{-2}$ & $1.81 \times 10^{-2}$ & $8.00 \times 10^{-3}$ \\
RMSEC & $9.08 \times 10^{-2}$ & $3.34 \times 10^{-2}$ & $3.67 \times 10^{-2}$ & $1.66 \times 10^{-2}$ \\
SEP & $8.83 \times 10^{-2}$ & $3.25 \times 10^{-2}$ & $3.56 \times 10^{-2}$ & $1.62 \times 10^{-2}$ \\
Bias & $-7.15 \times 10^{-4}$ & $-3.90 \times 10^{-4}$ & $-3.00 \times 10^{-4}$ & $-2.01 \times 10^{-3}$ \\
RE $(\%)$ & 0.526 & 0.515 & 0.567 & 0.391 \\
Determination coefficient $\left(r^{2}\right)$ & 0.9998 & 0.9999 & 0.9999 & 0.9999 \\
\hline
\end{tabular}

spiked human urine samples and satisfactory results were obtained (Table 8).

Pharmacokinetic studies on $\mathrm{PR}$ reported that it is excreted in urine mainly as conjugates $[12,13]$. Therefore, PR urine sample was exposed to enzymatic hydrolysis to obtain the total PR (free + conjugated). An aliquot equivalent to 400 units of $\beta$-glucuronidase enzyme with sulfatase activity was added to $1 \mathrm{~mL}$ of the collected urine sample after oral administration of the $\mathrm{PR}$ dose. The $\mathrm{pH}$ was adjusted to $5 \mathrm{using}$ acetate buffer and incubated at $37^{\circ} \mathrm{C}$ for $1 \mathrm{~h}$ [58]. The developed methods were applied to determine PR concentration for the same sample with and without enzymatic hydrolysis, before and after incubation. No significant difference that could be attributed to the increase in PR concentration due to enzymatic hydrolysis was obtained. This result provided evidence that the developed methods can determine total PR directly in urine without prior hydrolysis step. Furthermore, the published HPLC method [16] was employed to determine the total PR in the urine sample after enzymatic hydrolysis and the concentration determined was very closed from the concentration obtained using the developed methods with no enzymatic hydrolysis (Table 9).

Total PR excreted in urine was found in a concentration of 454.5 and $459.7 \mu \mathrm{g} \mathrm{mL}^{-1}$ and a cumulative (0-12 h) urine excretion of 89.1 and $90.1 \%$ of the administered dose using EDR and MCR-ALS, respectively. This is in agreement with previous studies that reported similar PR urine excretion percentage $[16,20]$. 
TABLE 6: Figures of merit of the MCR-ALS model for the validation set of AT, PR, HZ, and LV.

\begin{tabular}{lcccc}
\hline Parameters & AT & NP & HZ & LV \\
\hline Accuracy (mean $\pm \mathrm{SD})^{\mathrm{a}}$ & $99.71 \pm 1.16$ & $99.71 \pm 1.22$ & $99.94 \pm 0.85$ & \\
Precision: & & & 1.32 & 1.35 \\
Intraday (\% RSD) ${ }^{\mathrm{b}}$ & 1.57 & 1.24 & 1.65 & $0.01 \pm 0.79$ \\
Interday (\% RSD) & 1.70 & 0.0307 & 0.0461 & 0.72 \\
RMSEP & 0.2033 & 0.0284 & 0.0426 & 0.0366 \\
SEP & 0.1882 & $-8.34 \times 10^{-3}$ & $-1.08 \times 10^{-3}$ & 0.0339 \\
Bias & $6.63 \times 10^{-2}$ & 0.49 & 0.72 & $2.60 \times 10^{-3}$ \\
RE (\%) & 1.39 & 0.9999 & 0.9999 & 0.71 \\
$r^{2}$ & 0.9994 & & 0.9996 \\
\hline
\end{tabular}

${ }^{\mathrm{a}}$ Mean and standard deviation of 7 determinations. ${ }^{\mathrm{b}}$ Relative standard deviation of three different concentrations analyzed in triplicate within the same day.

${ }^{c}$ Relative standard deviation of three different concentrations analyzed in triplicate on three consecutive days.

TABle 7: Determination results of AT, PR, HZ, and LV in dosage forms by the proposed and reference methods.

\begin{tabular}{|c|c|c|c|c|c|c|c|c|}
\hline & \multirow[b]{2}{*}{ Parameter } & \multirow{2}{*}{$\begin{array}{l}\text { Conc. Claimed } \\
\quad\left(\mu \mathrm{g} \mathrm{mL}^{-1}\right)\end{array}$} & \multicolumn{2}{|c|}{ EDR } & \multicolumn{2}{|c|}{ MCR-ALS } & \multicolumn{2}{|c|}{ Reference method* } \\
\hline & & & $\begin{array}{l}\text { Conc. Found } \\
\left(\mu \mathrm{g} \mathrm{mL}^{-1}\right)\end{array}$ & $\%$ Recovery & $\begin{array}{c}\text { Conc. Found } \\
\left(\mu \mathrm{g} \mathrm{mL} \mathrm{mL}^{-1}\right)\end{array}$ & $\%$ Recovery & 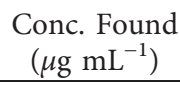 & \% Recovery \\
\hline \multirow{7}{*}{ AT } & Tenormin ${ }^{\circledR}$ tablets & 10 & 10.05 & 100.50 & 9.96 & 99.60 & 10.10 & 101.00 \\
\hline & & 15 & 14.85 & 99.00 & 15.05 & 100.33 & 15.08 & 100.53 \\
\hline & & 20 & 19.61 & 98.05 & 19.75 & 98.75 & 19.9 & 99.50 \\
\hline & Mean & & & 99.18 & & 99.56 & & 100.34 \\
\hline & $\pm \mathrm{SD}^{\mathrm{a}}$ & & & 1.24 & & 0.79 & & 0.77 \\
\hline & $t^{\mathrm{b}}$ & & & 3.50 & & 2.26 & & \\
\hline & $F^{\mathrm{b}}$ & & & 2.59 & & 1.07 & & \\
\hline \multirow{7}{*}{$\mathrm{PR}$} & Panadrex ${ }^{\circledR}$ tablets & 3 & 2.96 & 98.67 & 3.02 & 100.67 & 2.98 & 99.33 \\
\hline & & 5 & 5.05 & 101.00 & 4.93 & 98.60 & 5.03 & 100.60 \\
\hline & & 10 & 10.04 & 100.40 & 10.1 & 101.00 & 9.8 & 98.00 \\
\hline & Mean & & & 100.02 & & 100.09 & & 99.31 \\
\hline & $\pm \mathrm{SD}^{\mathrm{a}}$ & & & 1.21 & & 1.30 & & 1.30 \\
\hline & $t^{\mathrm{b}}$ & & & 0.79 & & 0.53 & & \\
\hline & $F^{\mathrm{b}}$ & & & 1.15 & & 1.00 & & \\
\hline \multirow{7}{*}{$\mathrm{HZ}$} & HCT georetic $25^{\circledR}$ tablets & 3 & 3.03 & 101.00 & 3.01 & 100.33 & 3.04 & 101.33 \\
\hline & & 5 & 4.92 & 98.40 & 4.96 & 99.20 & 4.98 & 99.60 \\
\hline & & 10 & 9.88 & 98.80 & 10.11 & 101.10 & 9.92 & 99.20 \\
\hline & Mean & & & 99.70 & & 99.77 & & 100.47 \\
\hline & $\pm \mathrm{SD}^{\mathrm{a}}$ & & & 1.84 & & 0.80 & & 1.23 \\
\hline & $t^{\mathrm{b}}$ & & & 2.31 & & 0.19 & & \\
\hline & $F^{\mathrm{b}}$ & & & 0.66 & & 1.41 & & \\
\hline \multirow{7}{*}{ LV } & Tavanic $^{\circledR}$ tablets & 3 & 2.98 & 99.33 & 3.01 & 100.33 & 2.98 & 99.33 \\
\hline & & 4 & 4.03 & 100.75 & 4.04 & 101.00 & 4.02 & 100.50 \\
\hline & & 5 & 5.03 & 100.60 & 5.01 & 100.20 & 5.03 & 100.60 \\
\hline & Mean & & & 100.23 & & 100.51 & & 100.14 \\
\hline & $\pm \mathrm{SD}^{\mathrm{a}}$ & & & 0.78 & & 0.43 & & 0.70 \\
\hline & $t^{\mathrm{b}}$ & & & 1.00 & & 0.89 & & \\
\hline & $F^{\mathrm{b}}$ & & & 1.22 & & 2.70 & & \\
\hline
\end{tabular}

${ }^{a}$ Standard deviation of the mean of percentage recovery from the label claim amount. ${ }^{\text {b}}$ Theoretical values for $t$ and $F$ are 4.30 and 19.00 at $(p=0.05)$, respectively. ${ }^{*}$ Reference methods for AT [3], PR [16], HZ [28] and LV [34].

TABLE 8: Determination results of AT, PR, HZ, and LV in spiked human urine samples using the proposed methods.

\begin{tabular}{|c|c|c|c|c|c|c|c|c|c|c|c|c|}
\hline \multirow{2}{*}{ Sample no. } & \multicolumn{4}{|c|}{ Conc. $\left(\mu \mathrm{g} \mathrm{mL}^{-1}\right)$} & \multicolumn{4}{|c|}{ EDR } & \multicolumn{4}{|c|}{ MCR-ALS } \\
\hline & AT & PR & $\mathrm{HZ}$ & LV & $\mathrm{AT}$ & $\mathrm{PR}$ & $\mathrm{HZ}$ & LV & $\mathrm{AT}$ & $\mathrm{PR}$ & HZ & LV \\
\hline 1 & 25 & 3 & 3.5 & 4 & 104.10 & 102.90 & 103.15 & 102.9 & 99.88 & 99.20 & 101.83 & 102.64 \\
\hline 2 & 10 & 5 & 4 & 1 & 97.81 & 101.30 & 104.7 & 105.35 & 101.41 & 97.94 & 100.86 & 102.12 \\
\hline 3 & 15 & 7 & 2 & 3 & 102.15 & 103.70 & 103.71 & 98.11 & 102.77 & 96.86 & 98.69 & 101.04 \\
\hline Mean & & & & & 101.35 & 102.63 & 103.85 & 102.12 & 101.35 & 98.00 & 100.46 & 101.93 \\
\hline$\pm \mathrm{SD}$ & & & & & 3.22 & 1.22 & 0.78 & 3.68 & 1.45 & 1.17 & 1.61 & 0.82 \\
\hline
\end{tabular}


TABLE 9: Determination of urinary excretion of PR and LV after administration of a single $500 \mathrm{mg}$ oral dose of PR or LV by healthy volunteers using EDR and MCR-ALS methods.

\begin{tabular}{lcccc}
\hline Compound & Parameter & EDR & MCR-ALS & Reference method* $^{*}$ \\
\hline PR & Concentration $\left(\mu \mathrm{g} \mathrm{mL} \mathrm{mL}^{-1}\right)$ & 454.5 & 459.7 & 457.4 \\
& Excretion $(0-12 \mathrm{~h})(\mathrm{mg})$ & 445.4 & 450.5 & 448.2 \\
\% Excretion $(0-12 \mathrm{~h})$ & 89.1 & 30.1 & 89.6 \\
\hline $\mathrm{LV}$ & Concentration $\left(\mu \mathrm{g} \mathrm{mL} \mathrm{mL}^{-1}\right)$ & 315.3 & 31.9 & 318.5 \\
& Excretion $(0-12 \mathrm{~h})(\mathrm{mg})$ & 302.7 & 62.9 & 305.8 \\
& $\%$ Excretion $(0-12 \mathrm{~h})$ & 60.5 & 61.2 \\
\hline
\end{tabular}

*Reference methods: PR [16] and LV [34].

On the other hand, when urine sample B (LV dose) was analyzed using the developed methods, LV was determined with cumulative $(0-12 \mathrm{~h})$ urinary excretion of 60.5 and $62.4 \%$ of the administered dose using EDR and MCR-ALS, respectively. The results are in agreement with previous studies which reported similar LV excretion percentage [34]. Furthermore, the obtained results were compared to a published HPLC method [34] and showed no significant difference as shown in Table 9. The urinary excretion results of PR and LV are summarized in Table 9.

3.4. Assessment of the Methods Greenness. Greenness assessment of the developed methods was accomplished using two different methods, namely, NEMI and Analytical Eco-Scale.

3.4.1. National Environmental Methods Index (NEMI). This assessment method utilizes a greenness profile symbol composed of four quadrants representing method aspects according to the following criteria: any of the chemicals used is persistent, bioaccumulative or toxic (PBT), hazardous, corrosive $(\mathrm{pH}<2$ or $>12)$, and the amount of waste generated $(>50 \mathrm{~g})$. If the method is green, all four quadrants will be colored green. However, if the procedure does not meet any of these aspects, the corresponding quadrant will be left blank (i.e., uncolored).

In the proposed methods, ethanol, which is considered a green solvent, was used to prepare the stock solutions and water was used as a solvent for all further dilutions and spectrophotometric measurements. Neither ethanol nor water is listed as PBT or hazardous. The $\mathrm{pH}$ is not corrosive and the produced waste is $<50 \mathrm{~g}$ per sample. Therefore, the proposed method passes the four criteria, and the four quadrants of the greenness profile are green.

3.4.2. Analytical Eco-Scale. In this method a more quantitative assessment is presented, where a numerical score is calculated to assess the method greenness, and high EcoScale score (i.e., $>75$ ) denotes the method greenness. Whenever the method uses hazardous chemicals, generates waste, has high energy consumption, or has exposure risk, penalty points are deducted from the total 100 points [47]. The high Eco-Scale score of the proposed methods (95) indicates the excellent greenness of the developed method (Table 10). Thus, they can be employed for the routine analysis of the studied drugs in pharmaceutical formulations
TABLE 10: Analytical Eco-Scale score for the proposed methods.

\begin{tabular}{lcc}
\hline Method items & Value & $\begin{array}{c}\text { Penalty } \\
\text { points } \\
\text { (PPs) }\end{array}$ \\
\hline $\begin{array}{l}\text { Reagents } \\
\text { (Water) Reagent amount }\end{array}$ & $<10 \mathrm{~mL}$ & 1 \\
$\begin{array}{l}\text { Reagent hazardous } \\
\text { (Ethanol) Reagent amount }\end{array}$ & $\begin{array}{c}\text { None } \\
\text { Reagent hazardous }\end{array}$ & 0 \\
$\begin{array}{l}\text { Total PPs (PPs of reagent } \\
\text { amount } \times \text { PPs reagent hazard) }\end{array}$ & $10 \mathrm{~mL}$ & 2 \\
$\begin{array}{l}\text { Instruments } \\
\text { Energy }\end{array}$ & $<0.1 \mathrm{kWh}$ per \\
$\begin{array}{l}\text { sample } \\
\text { Emission of } \\
\text { vapors and }\end{array}$ & 0 \\
$\begin{array}{l}\text { Waste } \\
\text { Total PPs (sum of instrument PPs) }\end{array}$ & $\begin{array}{l}1-10 \mathrm{~mL} \\
\mathbf{3}\end{array}$ & 3 \\
\hline $\begin{array}{l}\text { Total PPs (PPs reagent }+ \text { PPs } \\
\text { instrument) } \\
\text { Analytical Eco-Scale total score }\end{array}$ & $100-5=95$ & $\mathbf{9 5}$ \\
\hline
\end{tabular}

and urine samples with very few harmful effects on the environment.

\section{Conclusions}

Rapid, accurate, and cost-effective green nonconventional univariate and multivariate chemometrics-assisted spectrophotometric methods were developed for the determination of AT, PR, HZ, and LV in different pharmaceutical dosage forms. In addition, the proposed methods were successfully applied for the determination of the four analytes in spiked and real human urine samples and both methods provided comparable results. The assessment of the greenness profile of the two methods showed they represent an excellent green analysis of the studied drugs with very low harmful effects on the environment. Moreover, the proposed methods do not need any sample preparation, sophisticated HPLC instrumentation, or expensive solvents. Furthermore, the EDR method has the advantage of being simple and does not need any sophisticated mathematical algorithms needed for the MCR method. However, the main challenge in developing the EDR method is the selection of the optimum divisor to get selective and reproducible results. MCR-ALS 
method has the advantage over other first-order multivariate calibration methods of being able to produce good prediction even in the presence of inferences that are not represented in the calibration phase. The proposed methods can be used as a valid eco-friendly and simple cost-effective alternative to the commonly used chromatographic methods for the routine analysis of the studied drugs in dosage forms and human urine.

\section{Data Availability}

The data used to support the findings of this study are available from the corresponding author upon request.

\section{Conflicts of Interest}

The author has no conflicts of interest to declare.

\section{Acknowledgments}

This work was supported by the Deanship of Scientific Research, Imam Abdulrahman Bin Faisal University, Kingdom of Saudi Arabia (Grant No. Pharm-2017-250).

\section{References}

[1] J. J. Lilja, L. Juntti-Patinen, and P. J. Neuvonen, "Effect of rifampicin on the pharmacokinetics of atenolol," Basic \& Clinical Pharmacology \& Toxicology, vol. 98, pp. 555-558, 2006.

[2] A. El-Gindy, S. Emara, and A. Mostafa, "HPLC and chemometric-assisted spectrophotometric methods for simultaneous determination of atenolol, amiloride hydrochloride and chlorthalidone," Il Farmaco, vol. 60, pp. 269-278, 2005.

[3] B. Yilmaz, S. Arslan, and A. Asci, "HPLC method for determination of atenolol in human plasma and application to a pharmacokinetic study in Turkey," Journal of Chromatographic Science, vol. 50, pp. 914-919, 2012.

[4] N. S. Mohammed, "Method development and validation of atenolol using two hplc systems," International Journal of Pharmaceutical Sciences and Research, vol. 8, pp. 2706-2711, 2017.

[5] D. K. Sharma and P. Raj, "Simple and rapid spectrophotometry determination of atenolol and esmolol beta-blockers in pharmaceutical formulations and spiked water samples," International Journal of Pharmaceutical Sciences and Research, vol. 8, p. 5168, 2017.

[6] M. N. Khan, J. Ahmad, M. N. Jan, H. Gulab, and M. Idrees, "Development and validation of a new spectrophotometric method for the determination of cephalexin monohydrate in pure form and pharmaceutical formulations," Journal of the Brazilian Chemical Society, vol. 27, pp. 912-918, 2016.

[7] Y. Y. Chen and W. P. Yang, "Pharmacokinetic study of atenolol in rabbit blood by capillary electrophoresis with laser-induced fluorescence detection," Asian Journal of Chemistry, vol. 23, pp. 3958-3960, 2011.

[8] Y. G. Kuraeva, A. I. Kamenskaya, M. V. Vasil'eva, A. A. Stupnikov, and L. A. Onuchak, "Capabilities of capillary electrophoresis for the determination of atenolol and bisoprolol," Journal of Analytical Chemistry, vol. 71, pp. 396-401, 2016.
[9] B. Yilmaz and V. Akba, "Gas chromatography/mass spectrometry method for determination of atenolol in rabbit plasma," Asian Journal of Chemistry, vol. 23, pp. 54-58, 2011.

[10] E. Bakir, M. Gouda, A. Alnajjar, and W. E. Boraie, "Spectrofluorimetric method for atenolol determination based on gold nanoparticles," Acta Pharmaceutica, vol. 68, pp. 243-250, 2018.

[11] C. D. Oscier and Q. J. W. Milner, "Peri-operative use of paracetamol," Anaesthesia, vol. 64, pp. 65-72, 2009.

[12] A. Kulo, M. Y. Peeters, K. Allegaert et al., "Pharmacokinetics of paracetamol and its metabolites in women at delivery and post-partum," British Journal of Clinical Pharmacology, vol. 75, pp. 850-860, 2013.

[13] J. A. H. Forrest, A. H. Forrest, J. A. Clements, J. A. Clements, L. F. Prescott, and L. F. Prescott, "Clinical pharmacokinetics of paracetamol," Clinical Pharmacokinetics, vol. 7, pp. 93-107, 1982.

[14] S. F. Cook, A. D. King, J. N. van den Anker, and D. G. Wilkins, "Simultaneous quantification of acetaminophen and five acetaminophen metabolites in human plasma and urine by high-performance liquid chromatography-electrospray ionization-tandem mass spectrometry: method validation and application to a neonatal pharmacokinetic study," Journal of Chromatography B, vol. 1007, pp. 30-42, 2015.

[15] S. Abbasi, S. A. Haeri, and S. Sajjadifar, "Bio-dispersive liquid liquid microextraction based on nano rhamnolipid aggregates combined with molecularly imprinted-solid phase extraction for selective determination of paracetamol in human urine samples followed by HPLC," Microchemical Journal, vol. 146, pp. 106-114, 2019.

[16] L. S. Jensen, J. Valentine, R. W. Milne, and A. M. Evans, "The quantification of paracetamol, paracetamol glucuronide and paracetamol sulphate in plasma and urine using a single highperformance liquid chromatography assay," Journal of Pharmaceutical and Biomedical Analysis, vol. 34, pp. 585-593, 2004.

[17] Q.-y. Tan, R.-h. Zhu, H.-d. Li, F. Wang, M. Yan, and L.-b. Dai, "Simultaneous quantitative determination of paracetamol and its glucuronide conjugate in human plasma and urine by liquid chromatography coupled to electrospray tandem mass spectrometry: application to a clinical pharmacokinetic study," Journal of Chromatography B, vol. 893-894, pp. 162$167,2012$.

[18] A. Trettin, A. A. Zoerner, A. Böhmer et al., "Quantification of acetaminophen (paracetamol) in human plasma and urine by stable isotope-dilution GC-MS and GC-MS/MS as pentafluorobenzyl ether derivative," Journal of Chromatography B, vol. 879, pp. 2274-2280, 2011.

[19] J. Parojčić, K. Karljiković-Rajić, Z. Durić, M. Jovanović, and S. Ibrić, "Development of the second-order derivative UV spectrophotometric method for direct determination of paracetamol in urine intended for biopharmaceutical characterisation of drug products," Biopharmaceutics Drug Disposition, vol. 24, pp. 309-314, 2003.

[20] A. R. Khaskheli, A. Shah, M. I. Bhanger, A. Niaz, and S. Mahesar, "Simpler spectrophotometric assay of paracetamol in tablets and urine samples," Spectrochimica Acta Part A: Molecular Biomolecular Spectroscopy, vol. 68, pp. 747-751, 2007.

[21] T. Li, J. Xu, L. Zhao et al., “Au nanoparticles/poly (caffeic acid) composite modified glassy carbon electrode for voltammetric determination of acetaminophen," Talanta, vol. 159, pp. 356-364, 2016. 
[22] M. Lecoeur, G. Rabenirina, N. Schifano et al., "Determination of acetaminophen and its main metabolites in urine by capillary electrophoresis hyphenated to mass spectrometry," Talanta, vol. 205, Article ID 120108, 2019.

[23] H. Hasannejad, M. Takeda, K. Taki et al., "Interactions of human organic anion transporters with diuretics," Journal of Pharmacology \& Pharmacotherapeutics, vol. 308, pp. 10211029, 2004.

[24] S. A. Van Wart, S. E. Shoaf, S. Mallikaarjun, and D. E. Mager, "Population-based meta-analysis of hydrochlorothiazide pharmacokinetics," Biopharmaceutics Drug Disposition, vol. 34, pp. 527-539, 2013.

[25] J. De Vries and A. Voss, "Simple determination of hydrochlorothiazide in human plasma and urine by high performance liquid chromatography," Biomedical Chromatography, vol. 7, pp. 12-14, 1993.

[26] H. Albishri, D. Abd El-Hady, and R. A. Tayeb, "Eco-friendly simultaneous chromatographic determination of amiloride hydrochloride, atenolol, and hydrochlorothiazide in urine," Acta Chromatographica, vol. 27, pp. 461-476, 2015.

[27] W. Fang, W. Xie, J. K. Hsieh, and B. Matuszewski, "Development and application of HPLC methods with tandem mass spectrometric detection for the determination of hydrochlorothiazide in human plasma and urine using 96-well liquid-liquid extraction," Journal of Liquid Chromatography \& Related Technologies, vol. 28, pp. 2681-2703, 2005.

[28] D. Farthing, I. Fakhry, E. B. D. Ripley, and D. Sica, "Simple method for determination of hydrochlorothiazide in human urine by high performance liquid chromatography utilizing narrowbore chromatography," Journal of Pharmaceutical and Biomedical Analysis, vol. 17, pp. 1455-1459, 1998.

[29] L. Amendola, C. Colamonici, M. Mazzarino, and F. Botrè, "Rapid determination of diuretics in human urine by gas chromatography-mass spectrometry following microwave assisted derivatization," Analytica Chimica Acta, vol. 475, pp. 125-136, 2003.

[30] A. Mostafa, A. El-Gindy, and S. Emara, "Simultaneous spectrophotometric estimation of bisoprolol fumarate and hydrochlorothiazide in tablet formulation using partial leastsquares, principal component regression multivariate calibrations and RP-HPLC methods," Journal of Analytical \& Pharmaceutical Research, vol. 4, Article ID 00124, 2017.

[31] F. F. Mohammed, K. Badr El-Din, and S. M. Derayea, “Two smart spectrophotometric methods for simultaneous determination of Lisinopril and Hydrochlorothiazide in binary mixtures," Journal of Advanced Biomedical Pharmaceutical Sciences, vol. 2, pp. 47-53, 2019.

[32] H. Beitollahi and F. Ghorbani, "Benzoylferrocene-modified carbon nanotubes paste electrode as a voltammetric sensor for determination of hydrochlorothiazide in pharmaceutical and biological samples," Ionics, vol. 19, pp. 1673-1679, 2013.

[33] O. Szerkus, J. Jacyna, A. Gibas et al., "Robust HPLC-MS/MS method for levofloxacin and ciprofloxacin determination in human prostate tissue," Journal of Pharmaceutical Biomedical Analysis, vol. 132, pp. 173-183, 2017.

[34] A. El-Gindy, S. Emara, and A. Mostafa, "UV partial leastsquares calibration and liquid chromatographic methods for direct quantitation of levofloxacin in urine," Journal of AOAC International, vol. 90, pp. 1258-1265, 2007.

[35] S. Ghimire, K. van Hateren, N. Vrubleuskaya, R. Koster, D. Touw, and J.-W. Alffenaar, "Determination of levofloxacin in human serum using liquid chromatography tandem mass spectrometry," Journal of Applied Bioanalysis, vol. 4, p. 3152, 2018.
[36] O. Abdel-Aziz, M. F. Abdel-Ghany, R. Nagi, and L. AbdelFattah, "Application of Savitzky-Golay differentiation filters and Fourier functions to simultaneous determination of cefepime and the co-administered drug, levofloxacin, in spiked human plasma," Spectrochimica Acta Part A: Molecular and Biomolecular Spectroscopy, vol. 139, pp. 449-455, 2015.

[37] M. Rkik, M. B. Brahim, and Y. Samet, "Electrochemical determination of levofloxacin antibiotic in biological samples using boron doped diamond electrode," Journal of Electroanalytical Chemistry, vol. 794, pp. 175-181, 2017.

[38] A. Rusu, P. Antonoaea, A. Ciurba, M. Birsan, G. Hancu, and N. Todoran, "Development of a rapid capillary zone electrophoresis method to quantify levofloxacin and meloxicam from transdermal therapeutic systems," Studia Universitatis Babes-Bolyai Chemia, vol. 64, 2019.

[39] A. Gałuszka, Z. Migaszewski, and J. Namieśnik, "The 12 principles of green analytical chemistry and the significance mnemonic of green analytical practices," TrAC Trends in Analytical Chemistry, vol. 50, pp. 78-84, 2013.

[40] H. Shaaban and A. Mostafa, "Sustainable eco-friendly ultrahigh-performance liquid chromatographic method for simultaneous determination of caffeine and theobromine in commercial teas: evaluation of greenness profile using NEMI and eco-scale Assessment tools," Journal of AOAC International, vol. 101, pp. 1781-1787, 2018.

[41] P. T. Anastas and J. C. Warner, Green Chemistry: Theory and Practice, TPB, Oxford University Press, New York, NY, USA, 2012.

[42] M. A. Korany, H. Mahgoub, R. S. Haggag, M. A. Ragab, and O. Elmallah, "Chemometrics-assisted spectrophotometric green method for correcting interferences in biowaiver studies: application to assay and dissolution profiling study of donepezil hydrochloride tablets," Spectrochimica Acta Part A: Molecular Biomolecular Spectroscopy, vol. 199, pp. 328-339, 2018.

[43] A. Mostafa, H. Shaaban, M. Almousa, M. Al Sheqawi, and M. Almousa, "Eco-friendly pharmaceutical analysis of multicomponent drugs coformulated in different dosage forms using multivariate curve resolution and partial least squares: a comparative study," Journal of AOAC International, vol. 102, pp. 465-472, 2019.

[44] A. Mostafa and H. Shaaban, "Quantitative analysis and resolution of pharmaceuticals in the environment using multivariate curve resolution-alternating least squares (MCRALS)," Acta. Pharm. vol. 69, pp. 217-231, 2019.

[45] L. Keith, L. Gron, and J. Young, "Green analytical methodologies," Chemical Reviews, vol. 107, pp. 2695-2708, 2007.

[46] M. Tobiszewski, M. Marć, A. Gałuszka, and J. Namieśnik, "Green chemistry metrics with special reference to green analytical chemistry," Molecular Cells, vol. 20, pp. 1092810946, 2015.

[47] A. Gałuszka, Z. M. Migaszewski, P. Konieczka, and J. Namieśnik, "Analytical Eco-Scale for assessing the greenness of analytical procedures," TrAC Trends in Analytical Chemistry, vol. 37, pp. 61-72, 2012.

[48] R. Tauler, "Multivariate curve resolution applied to second order data," Chemometrics and Intelligent Laboratory Systems, vol. 30, pp. 133-146, 1995.

[49] W. Windig and J. Guilment, "Interactive self-modeling mixture analysis," Analytical Chemistry, vol. 63, pp. 14251432, 1991.

[50] T. Azzouz and R. Tauler, "Application of multivariate curve resolution alternating least squares (MCR-ALS) to the 
quantitative analysis of pharmaceutical and agricultural samples," Talanta, vol. 74, pp. 1201-1210, 2008.

[51] A. de Juan and R. Tauler, "Chemometrics applied to unravel multicomponent processes and mixtures: revisiting latest trends in multivariate resolution," Analytica Chimica Acta, vol. 500, pp. 195-210, 2003.

[52] R. R. de Oliveira, K. M. G. de Lima, R. Tauler, and A. de Juan, "Application of correlation constrained multivariate curve resolution alternating least-squares methods for determination of compounds of interest in biodiesel blends using NIR and UV-visible spectroscopic data," Talanta, vol. 125, pp. 233-241, 2014.

[53] J. Jaumot, A. de Juan, and R. Tauler, "MCR-ALS GUI 2.0: new features and applications," Chemometrics and Intelligent Laboratory Systems, vol. 140, pp. 1-12, 2015.

[54] R. G. Brereton, "Multilevel multifactor designs for multivariatecalibration," Analyst, vol. 122, pp. 1521-1529, 1997.

[55] O. Abdel-Aziz, A. M. El Kosasy, and S. M. E. Okeil, "Comparative study for determination of some polycyclic aromatic hydrocarbons "PAHs" by a new spectrophotometric method and multivariate calibration coupled with dispersive liquidliquid extraction," Spectrochimica Acta Part A: Molecular and Biomolecular Spectroscopy, vol. 133, pp. 119-129, 2014.

[56] ICH Guideline, "Validation of analytical procedures: text and methodology Q2 (R1)," in Proceedings of the International Conference on Harmonization, Geneva, Switzerland, 2005.

[57] K. S. Booksh and B. R. Kowalski, "Theory of analytical chemistry," Analytical Chemistry, vol. 66, pp. 782A-791A, 1994.

[58] J. L. Vila-Jato, J. Blanco, and M. J. Alonso, "The effect of the molecular weight of polyethylene glycol on the bioavailability of paracetamol-polyethylene glycol solid dispersions," Journal of Pharmacy Pharmacology, vol. 38, pp. 126-128, 1986. 